\title{
El español en los Andes durante la evangelización del Perú colonial desde la perspectiva académica alemana
}

\author{
Ofelia Huamanchumo de la Cuba
}

\begin{abstract}
RESUMEN
Este artículo presenta un recuento de las investigaciones y publicaciones hechas por filólogos e investigadores de universidades alemanas en torno al español que se habló y se escribió en los Andes —una de cuyas variedades se conoce como «español o castellano andino»— en la etapa de la evangelización del Perú de los siglos xvi y xvII, que es el marco tópico y cronológico de los temas revisados en los artículos que comprenden el presente Dossier. Aquí se expondrán de manera resumida: la evolución del interés por el tema del español en América, los métodos impulsados en las investigaciones, las diferentes perspectivas adoptadas y, por último, los principales aportes de los más recientes estudios.
\end{abstract}

Palabras clave: español andino, textos coloniales, evangelización, colonia, Perú, hispanistas alemanes 


\begin{abstract}
This article presents an account of the research and publications done by philologists and academic researchers from German universities around the Spanish in the Andes —one of its varieties is the «Andean Spanish» - at the stage of the evangelization of Peru in the sixteenth and seventeenth centuries, which is the topic and the time frame of the topics reviewed articles that comprise this Dossier. Here will be presented in summary form: the evolution of interest in the themes about the Spanish in America; the promoted methods used; the different perspectives adopted; and finally, the main contributions of the more recent studies.
\end{abstract}

Keywords: Andean Spanish, Colonial texts, evangelization, Colony, Peru, German Hispanists

\title{
INTRODUCCIÓN
}

EL INTERÉS DE ESTUDiOSOS Y ACADÉMICOS ALEMANES por el español que se habló en los Andes coloniales ha sido mostrado en las últimas tres décadas en diferentes estudios sobre el español en América, desde los enfoques de distintas disciplinas lingüísticas. Dicho interés parece haber estado relacionado desde sus inicios con estudios con cierta predilección por temas precolombinos.

Un retroceso hacia los posibles orígenes de la tendencia entre los investigadores alemanes hacia lo prehispánico puede remontarse, para la realidad del Perú, hasta las figuras de Alexander von Humboldt (1769-1859) o Ernst Wilhelm Middendorf (1830-1908). El primero destacó en el estudio de las costumbres autóctonas de los pueblos que visitó y su conexión con el pasado anterior a la cultura europea, mientras que el segundo se interesó por algunas lenguas autóctonas, como el quechua, el aymara y una de la costa norte, que él llamó lengua «muchik». Después, desde la última década del xix, las investigaciones de las lenguas prehispánicas y su 
interrelación con el idioma español llegado de Europa a América se inició con el profesor Rudolf Lenz (1863-1938) — doctor en Lingüística por la Universidad de Bonn, dedicado a la investigación de las lenguas araucanas en Chile_-, quien fundó una rama de las ciencias del lenguaje: la de las lenguas en contacto, basada en el estudio de los estratos lingüísticos (Roth 1995: 35). Ese fue el primer gran aporte y la base para los enfoques que se desarrollarán luego, que tendrán que ver con la pregunta por el modo en que se produjeron esos contactos lingüísticos que dieron origen, en el caso de los territorios sudamericanos, a la variedad lingüística que se conocerá como «castellano andino» (Cerrón-Palomino 1976) o «español andino» (Rivarola 1989).

Pasará un siglo más desde los impulsos del profesor Lenz para que el interés en los textos de la época colonial americana experimente una intensificación de parte de muchos más estudiosos alemanes, pues fueron las celebraciones por los 500 años de la llegada de los españoles a tierras americanas las que promovieron dicho reemprendimiento. Según los recuentos que en ese entonces hizo la profesora Birgit Scharlau (1990), luego de la tradición alemana iniciada por Humboldt, y olvidada por mucho tiempo, el interés por los códices mayas y los documentos hispánicos e indígenas de la época colonial se extendió hacia especialistas de otras disciplinas, quienes lograron hacer accesibles los diversos documentos al público alemán gracias a reconstrucciones, traducciones, desciframientos y análisis, pero sobre todo debido a un nuevo concepto de «texto». Este ya no se entendía como unidad monolítica y homogénea, sino como una pluralidad de elementos culturales, lingüísticos y mediales. Del mismo modo, los textos de origen indígena o mestizo fueron presentados con el fin de desenterrar la voz de las culturas prehispánicas, lo cual llamó además la atención sobre la problemática de la oralidad y la literalidad, al igual que acerca de las formas en que la palabra indígena aparecía en los textos coloniales. Para la estudiosa alemana, la óptica de poner más atención en el análisis de los contenidos que 
en sus formas de transmisión había empezado a cambiar pocos años antes, hacia los setenta, cuando los investigadores, por una parte, intentaron visualizar las ideologías de sus autores, así como el trasfondo intelectual y literario de los textos en general, y por otra, se concentraron, a partir de los textos, en reconstruir determinadas relaciones culturales e idiomáticas de la etapa colonial.

A finales de los setenta la lingüística histórico-comparativa se empezó a consolidar también en la filología andina en manos de peruanistas, lingüistas peruanos y extranjeros, que inauguraron métodos de análisis filológicos y de la ecdótica para aplicarlos en la interpretación de los textos coloniales. Así lo ha señalado el profesor Cerrón-Palomino en un estudio, en el que fijó a la década de 1960 como hito en el desarrollo de la lingüística amerindia, pues en esos años se publicaron estudios descriptivistas sobre lenguas o dialectos nunca antes abordados e investigaciones de corte diacrónico, a pesar de que muchas de las fuentes documentales coloniales no presentaban un nivel de transcripción paleográfica útil para un estudio rigurosamente lingüístico y aún no se había dado el estudio sincrónico y diacrónico de las realidades lingüísticas que se querían estudiar (2006: 109-113).

En las universidades de Alemania, en los tiempos previos a las celebraciones por los 500 años del Descubrimiento, se observará una tendencia a ampliar el interés tradicional de estudiar los textos coloniales desde las perspectivas de disciplinas como la ciencia literaria y la lingüística hacia planteamientos tanto sociohistóricos como interculturales (Neuschäfer 1996: 80). Eso debido a que también en los noventa la mirada académica alemana, en general, se dirigió sobre todo a la época histórica de la Modernidad, y alcanzó como resultado hacia la década siguiente la cúspide de lo que se dio en llamar un «boom de los estudios hispánicos» en el campo de la filología (Kabatek 2005). El estudio de esa etapa de la historia europea se extendió hacia el de ese otro trasfondo histórico común a los textos coloniales escritos tanto en español como en lenguas 
amerindias coloniales por hablantes nativos del español así como por indios ${ }^{1}$ bilingües, que fue el de la evangelización americana. Este, como otros temas de hispanística, mantiene hasta hoy en la academia alemana un interés muy vigente y con amplias perspectivas a futuro (Kabatek 2014).

\section{El español en América colonial: lenguas y teXtos en CONTACTO}

A lo largo de la década de 1990, los estudios por parte de académicos alemanes vuelcan la mirada hacia los textos americanos coloniales con el afán de observar ya no solo su carácter literario, sino para analizarlos desde el punto de vista de disciplinas como la historia de la lengua, la pragmática y la lingüística textual. Un acontecimiento que llamó significativamente la atención sobre el español colonial fue el Simposio del Instituto Ibero-Americano de Berlín, realizado el 23 y 24 de abril de 1992, en el que se hizo un llamado a comprender el estudio de las fuentes coloniales insistiendo en los aspectos pragmático y social. Las actas de aquella celebración se publicaron en El español de América en el siglo XVI (Lüdtke 1994), en cuyas diferentes contribuciones se hacen aportes originales que sentarán las bases teóricas para futuros estudios concentrados en el español del Perú; entre otros:

a) apostar por el estudio de las tradiciones textuales en los tipos textuales como cuestión primordial para no alterar los resultados de los análisis gramaticales y léxicos de los textos (Wesch 1994: 57-71). ${ }^{2}$

1. El término «indio» alude a los habitantes nacidos en el ente geopolítico que comprendió las llamadas Indias Occidentales.

2. Andreas Wesch ya había publicado el año anterior una edición comentada de la Información de los Jerónimos (Santo Domingo, 1517) basada en un análisis lingüístico 
b) hacer un llamado a considerar el nivel de competencia lingüística de los emisores y la impronta oral de los textos escritos por semicultos (Oesterreicher 1994a: 155-190). ${ }^{3}$

c) profundizar el estudio del contacto de lenguas a partir del análisis de textos elaborados por indios bilingües, de español y quechua (Rivarola 1994: 191-209). ${ }^{4}$

d) en general, despertar el interés por el estudio de textos de carácter marginal —es decir, de textos que no se encontraran en el conjunto de las obras literarias canónicas ni de las crónicas historiográficas clásicas-, considerados así, en sentido amplio, aquellos textos escritos por historiadores humanistas, cronistas de convento, secretarios y oficiales. ${ }^{5}$

Por otra parte, se publica el volumen Lengua y cultura en el Caribe Hispánico (Lüdtke y Perl 1994), en el que se insiste en considerar que las clases textuales indianas son atravesadas por modificaciones respecto al contenido y la forma, como fruto ya sea de la competencia del autor como de las circunstancias históricas dadas y del contexto extralingüístico.

de dicho documento y las clases textuales «información»e «instrucción» (1993). El principal aporte de los estudios de este investigador fue llamar la atención sobre los dos niveles de complejidad del texto al momento de analizar su saber expresivo: el nivel de los actos comunicativos elementales y el nivel de la clase de texto. La conciencia explícita de este último por parte de sus autores les permitiría el uso de las tradiciones y convenciones textuales en la conscriptio del texto.

3. Los catedráticos Peter Koch y Wulf Oesterreicher ya habían publicado un estudio sobre la lengua hablada en tres idiomas románicos (español, francés e italiano) en 1990, cuyos planteamientos sentarán las bases teóricas de estudios posteriores sobre oralidad y escrituralidad. Véase al respecto el capítulo II de aquel estudio, en la edición traducida al español (Koch y Oesterreicher 2007).

4. Rivarola ya había problematizado el tema del contacto de lenguas, y sobre todo del español andino, en un congreso en Berlín, Alemania; véase Rivarola (1989).

5. Aquí se entiende por textos coloniales «clásicos» los publicados, por ejemplo, en la colección de Esteve Barba (1992). 
Ese mismo año, con las contribuciones de una publicación académica sobre las relaciones entre lingüística, retórica y literatura, en homenaje al profesor Wolf-Dieter Stempel, de la Universidad de Tubinga, se profundizará el estudio de ese otro tipo de textos de la producción historiográfica indiana en su sentido amplio, la cual no solo está dada en el discurso de documentos editados y publicados en su época, sino documentos marginales de carácter privado, como los escritos del soldado Alonso Borregán (Oesterreicher 1994b: 379-418), que fueron producidos en el marco de una petición judicial, pero que podrían conformar en su esencia una crónica de lo acontecido en los primeros años de la conquista del Perú desde el punto de vista de un modesto soldado. ${ }^{6} \mathrm{Al}$ año siguiente destaca otra contribución del mismo profesor en el marco de un estudio sobre las perspectivas culturales de la escritura y el proceso de escribir (Oesterreicher 1995: 98-120), donde se analiza un suceso del pasado americano y sus diferentes representaciones (la masacre de Cholula, 1519) y se demuestra la relevancia de la pregunta por las condiciones extralingüísticas en la producción de un texto, por el contexto en que surge, por los receptores y por la historia de los efectos ocurridos como consecuencia de ello.

Por otro lado, y casi paralelamente, en los años noventa se intensificó también el interés de los académicos alemanes por las lenguas amerindias en su contacto con el español llegado a América. Fueron relevantes en la dirección de esas investigaciones los aportes

6. En la misma línea de investigación se publicará más tarde el estudio sobre Juan Ruiz de Arce y la edición de sus memorias (Stoll 2002), así como el estudio de Alonso Borregán y la edición crítica de su crónica (Stoll y Vásquez 2011). Por otro lado, la investigadora italiana Chiara Albertin, quien participó en varias oportunidades en conferencias y simposios en la LMU, publicó un estudio —asesorada por el profesor Rivarola en la Universidad de Padua- y la edición crítica de De las costumbres antiguas de los naturales del Pirú (2008) bajo el mismo sello editorial que las dos publicaciones mencionadas, en la colección Textos y Documentos Españoles y Americanos, dirigida por el profesor Oesterreicher, entre otros. 
compilados por el profesor Klaus Zimmermann. Del libro Lenguas en contacto en Hispanoamérica. Nuevos enfoques (1995b), destacan las contribuciones:

a) sobre aspectos teóricos y metodológicos en la investigación sobre contacto de lenguas (Zimmermann 1995a: 9-34).

b) sobre la influencia de las lenguas amerindias en el castellano (Roth 1995: 35-50).

c) de una aproximación histórica a los contactos de lenguas en Perú (Rivarola 1995: 135-159).

Del mismo modo, en el libro La descripción de las lenguas amerindias en la época colonial (Zimmermann 1997), el editor ya habla de una nueva corriente de investigación de historiografía lingüística y lingüística descriptiva que centra su interés en el análisis de los métodos de descripción de las lenguas exóticas en «gramáticas» y «vocabularios» coloniales; destaca así en el tema que aquí interesa la segunda parte de aquel libro, «II. Estudios sobre gramáticas y vocabularios de la Región Andina», donde se estudia las características de dichas gramáticas de carácter didáctico, elaboradas por misioneros y religiosos que estuvieron en contacto con lenguas andinas en la época colonial. ${ }^{7}$

\section{LO HABLADO Y LO ESCRITO EN DOCUMENTOS INDIANOS}

Hacia la segunda mitad de los noventa se acentuó el interés por el estudio de textos de carácter marginal en los que se evidencia la presencia de un escribiente que redacta lo que le dictan o cuentan. Asimismo se llegó a afianzar una corriente de investigación que

7. Estas primeras reflexiones serán el comienzo de lo que más tarde Zimmermann expondrá en el primer congreso internacional (en Oslo, 2003) de la materia conocida como «Lingüística misionera», tema sobre el que volveré más adelante. 
pondrá atención a la diversidad textual y el nivel de instrucción de los autores. A ello le seguirá la pregunta por los rasgos de oralidad presentes en textos escritos, ya sea por haber sido dictados o redactados por «semicultos». Así, en el volumen El español bablado y la cultura oral en España e Hispanoamérica (Kotschi, Oesterreicher y Zimmermann 1996) son de relevancia dos aportaciones:

a) el estudio del lenguaje espontáneo y la retórica epistolar en cartas de emigrantes a Indias (Cano Aguilar 1996: 375-404).

b) las reflexiones metodológicas sobre la presencia de lo hablado en lo escrito (Oesterreicher 1996: 317-340).

Esa línea de estudio siguió también el libro Konquistadoren als Historiographen (Stoll 1997), dedicado al análisis de diferentes crónicas relativas a la conquista del Perú, en las que se demuestra las consecuencias en la producción textual de los distintos niveles de competencia historiográfica y lingüística de sus autores. A ello se sumó el mismo año en el artículo «Cajamarca 1532. Diálogo y violencia. Los cronistas y la elaboración de una historia andina» (Oesterreicher 1997) la problematización de la idea de la confrontación entre cultura escrita europea y mundo americano, y de las asimetrías que podían resultar de esa comunicación hispanoindígena, que producirán textos con elementos provenientes tanto de la cultura letrada hispana como de la ágrafa andina.

La mayor apertura de los estudios académicos alemanes hacia textos marginales y el creciente interés en una mayor diversidad de textos entre los objetos de investigación se reflejó también en las contribuciones reunidas en el volumen Competencia escrita, tradiciones discursivas y variedades lingüisticas. Aspectos del español europeo y americano en los siglos ХИІ у ХVII (Oesterreicher, Stoll y Wesch 1998), entre las que destacan los aportes sobre:

a) algunas cuestiones de la transcripción de declaraciones orales en documentos indianos (Cano Aguilar 1998: 219-242). 
b) la observación de la oralidad en las Actas de la Inquisición (Eberenz 1998: 243-266). ${ }^{8}$

c) la presentación de una tipología lingüística de textos administrativos y jurídicos españoles de los siglos XV al XVII (Wesch 1998: 187-217).

d) el estudio de modelos y transformaciones en los géneros de la historiografía indiana (Stoll 1998: 143-168).

Este libro subrayó además la importancia del estudio de la «autoría» de los textos analizados (testigos, escribanos, notarios, soldados, conquistadores) y motivó la ampliación del campo de estudio hacia las actas judiciales de procesos eclesiásticos e inquisitoriales. Ello despertaría más tarde el interés en los documentos inquisitoriales americanos e incentivaría la profundización del tema de las llamadas «tradiciones discursivas».

\section{UNA NUEVA FILOlogía: EL ESTUdio de LAS TRADICIONES DISCURSIVAS}

La primera década del nuevo milenio se abrió con un interés especial por parte de la academia alemana — como se mencionó líneas arriba - por la época de la Modernidad. En la Universidad LudwigMaximilian de Múnich (LMU) se inició, en la sección de proyectos especiales, uno de enormes ambiciones científicas, Pluralización y autoridad en la Temprana Edad Moderna (Siglos XV-XVII), que comprendía a su vez tres grandes campos de estudio: (a) ambivalencias del discurso letrado, (b) órdenes del saber y (c) pragmatización de la autoridad. En el segundo de ellos se constituyeron — entre otros de otras disciplinas humanas - dos proyectos que interesan aquí. Uno, «Pragmatización de los discursos historiográficos y jurídicos en la colonización española

8. Sobre actas inquisitoriales, por el mismo autor, véase Eberenz y De la Torre (2003). 
de América» (Proyecto C6) y otro, «Nuevo y Viejo Mundo-Tradiciones del saber en la cristianización de América» (Proyecto B5), ambos bajo la dirección del profesor Oesterreicher, del Instituto de Romanística de la LMU. El primero de ellos tuvo como objetivo principal el estudio del discurso en los textos coloniales, oficiales y marginales, donde jugara un rol importante la consideración de las tradiciones discursivas; concepto entendido no como «género» o «tipo de texto», sino fundamentado en la historicidad de los modelos discursivos que determinan toda producción discursiva y textual (Oesterreicher 2005: xii). El proyecto B5, por su parte, tuvo dos etapas. En una primera, el proyecto trabajó con textos de contenido gramatical que documentaron los avances del conocimiento de lenguas amerindias, y que sirvieron para transmitirse a las siguientes generaciones de misioneros. Se evaluó el modelo del latín como base y además la sola intuición para la construcción de las gramáticas, artes y vocabularios coloniales. ${ }^{9}$ Fruto de ello fue el estudio de grandes dimensiones que el profesor Schmidt-Riese llevó a cabo (y que culminó en una tesis postdoctoral, Habilitierungsschrift, titulada Reducere ad artem), en el que se observan las transformaciones sufridas en la categorización de los elementos gramaticales de las lenguas exóticas que los misioneros y religiosos intentaron describir sistemáticamente (Schmidt-Riese 2004). Con ello también se llamaría la atención sobre la investigación de los «paratextos» (Prólogo, Al lector, etc.) de las voluminosas obras coloniales, en los que se reflejarían informaciones decisivas para contextualizar lingüísticamente los objetos de estudio. ${ }^{10}$

Paralelamente a estos acontecimientos, al inicio de la década se publicó el libro Lengua medievaly tradiciones discursivas en la Península Ibérica. Descripción gramatical-Pragmática histórica-Metodología. En la Introducción (Jacob y Kabatek 2001a: vii-xviii), sus editores

9. Sobre el tema de las lenguas y las misiones en América, y el estatus del latín en las estrategias de cristianización en Europa y América, véase Oesterreicher (2003).

10. Sobre paratextos en la historiografía indiana, véase Stoll (2013). 
retoman para la academia alemana el tema de una «nueva filología», que buscaba reconciliar el tradicional abismo entre la filología, como disciplina que investiga los textos, y la lingüística, como ciencia de las lenguas; todo para estudiar las tradiciones discursivas desde un punto de vista no solo histórico, sino también social. En este volumen se presentaron reflexiones interesantes que invitaban a ampliarse metodológicamente hacia los géneros de la temprana edad moderna y, en consecuencia, a los textos coloniales: por un lado, se impulsa la tarea hermenéutica de la recontextualización; para el caso de los textos jurídicos, historiográficos y literarios se trata de una recuperación de las múltiples posibilidades semióticas del evento comunicativo, es decir, su reconstrucción sociopragmática (Oesterreicher 2001: 199-232); y por otra parte, se propone partir de la relación entre texto, tradición textual y lengua, para poder plantear de manera adecuada la cuestión del cambio lingüístico y su relación con la creación de nuevas tradiciones discursivas (Kabatek 2001: 97-132). ${ }^{11}$ Un estudio ejemplar en la línea de evaluar la impronta de las diferentes tradiciones discursivas en la competencia lingüística de un autor de texto privado lo constituyó la edición crítica de los escritos de Juan Ruiz de Arce, donde se pone además de relieve la importancia de observar el marco sociopragmático de los textos (Stoll 2002). ${ }^{12}$

Por otra parte, y también a comienzos de la década, el profesor Rivarola publicó un corpus de textos redactados por indios bilingües, entre los siglos XV y XVII, titulado Español andino (Rivarola 2000), con el que llamará la atención sobre ese tema entre los investigadores alemanes; a lo que se agregaría el libro Castellano andino del profesor Cerrón-Palomino (2003), que reunió observaciones sobre aspectos

11. Para ampliar el tema de las tradiciones discursivas, véase Kabatek (2005) y Oesterreicher (2005).

12. Véase también Stoll y Vásquez (2011) sobre los escritos privados del soldado Alonso Borregán. 
sociolingüísticos, pedagógicos y gramaticales, cuestiones que se verán aplicadas en otras publicaciones de caso, como las que salieron junto con un artículo suyo en el número especial de la revista alemana RILI (Revista Internacional de Lingüistica Iberoamericana) dedicada al tema del español en contacto con otras lenguas (CerrónPalomino 2004). ${ }^{13}$ Ese mismo año se publicó también una selección de contribuciones que participaron en el primer congreso de la llamada «lingüística misionera», llevado a cabo en Oslo un año antes, que despertará el interés entre los académicos alemanes aún más por el estudio de ese tipo de textos que tuvieron un rol especial en la empresa de la evangelización de América. Así, la contribución del profesor Zimmermann propone la construcción del perfil del objeto de la historiografía lingüística misionera (2004). Por otro lado, también en 2003 se llevará a cabo el $14^{\circ}$ Congreso Internacional de Hispanistas Alemanes en Ratisbona, en el que se insistirá en el tema del contacto de lenguas en la revisión de la historia del español de América con la consideración de un nuevo enfoque que impulse más la idea del español como lengua pluricéntrica. Las contribuciones de dicha Sección se publicaron un año después (Neumann, Noll y Zimmermann 2005).

\section{InVestigación de los discursos de la Catequesis Y EL Derecho Indiano}

Hacia la segunda mitad de la primera década del nuevo milenio se inició la siguiente etapa del mencionado Proyecto B5 de la LMU: «Nuevo y Viejo Mundo-Tradiciones del saber en la cristianización de América», en la que se pondrá atención no solo al estudio del conocimiento de las lenguas amerindias que los misioneros tuvieron,

13. Esta revista volverá más tarde a dedicar otro número especial al tema del contacto del español con otras lenguas en América (Martínez y Palacios 2010). 
sino a investigar el discurso del dominio de la religiosidad europea (los textos religiosos, las oraciones de la catequesis, etc.), que tuvo que tomar en cuenta a las prácticas religiosas y tradiciones del saber indígena; con lo cual se abría paso a la amenaza de los sincretismos religiosos y, por ende, del peligro de la misión evangelizadora. Por otro lado, la persistencia en la práctica de ciertas creencias y supersticiones indígenas impulsó las campañas de extirpación de las idolatrías, que finalmente constituyeron el marco sociohistórico para muchos textos de carácter jurídico y eclesiástico. Todos estos temas fueron objeto de estudio para intentar revelar los efectos pluralizadores de la transmisión y la contaminación del discurso europeo catequético en las zonas de los mayas y en las andinas. Es así como en el año 2005, también en el marco del Congreso Internacional de Hispanistas Alemanes, en Bremen, se organizó una Sección que estudió las fronteras borrosas entre el discurso de la Catequesis y el discurso del Derecho Indiano, cuyas conferencias contribuyeron a mostrar y corroborar la condición de interrelación que hubo en general entre los diferentes sistemas coloniales: jurídico, administrativo, religioso, social, cultural y lingüístico. ${ }^{14}$

Por otra parte, se publica en español la versión ampliada y revisada del libro Lengua bablada en la Romania: español, francés, italiano (Koch y Oesterreicher 2007), así como también otro gran aporte a la revisión de las nociones en torno a las tradiciones discursivas: el volumen Sintaxis histórica del español y cambio lingüístico. Nuevas perspectivas desde las tradiciones discursivas, que contiene en su Introducción un resumen de la importancia de los estudios que tienen como paradigma las tradiciones discursivas en la descripción lingüística y gramatical del español (Kabatek 2008). A estas reflexiones se sumó otra publicación primordial con un recuento de caracterizaciones histórico-comunicativas, relevantes para los estudios de textos jurídico-administrativos, religiosos y de literatura

14. Véase las contribuciones publicadas en Schmidt-Riese (2010c). 
catequética, para centrar el análisis del dominio del discurso de la historiografía hispanoamericana, mostrando en qué forma las tensiones y conflictos de la primera etapa colonial son representados y trabajados a nivel lingüístico y discursivo (Oesterreicher 2009).$^{15}$ Todas estas reflexiones de la nueva filología formarán parte central del marco teórico de las investigaciones en el rubro de los discursos de la Catequesis y del Derecho Indiano.

Es así como se da espacio en las publicaciones alemanas a artículos sobre normas y tradiciones discursivas específicamente de los inicios del español de América, vistos en textos de bilingües en el Perú (Garatea 2008a, 2008b). Por su parte, el profesor Rivarola volverá sobre los documentos bilingües y los estudios de córpora, elaborados en el marco de las campañas de extirpación de las idolatrías del siglo XVII y en actas de la Inquisición, entre otros documentos, donde se darán también las primeras muestras del «español andino» (2008, 2009). Por otro lado, los conceptos de las pluralizaciones, o multiplicación de saberes en los nuevos territorios americanos, se van redondeando para entender la época de la temprana edad moderna, y se legitiman como marco teórico imprescindible para comprender, por ejemplo, los estudios sobre las Gramáticas coloniales (Schmidt-Riese 2010b).

\section{El español en los Andes y la evangelización del Perú}

En los últimos estudios de los investigadores surgidos de la escuela de la LMU y otros ligados a ella, investigar sobre el español en América, el español en los Andes y el español del Perú ha supuesto observar los fenómenos lingüísticos en el marco decisivo

15. El segundo artículo del Dossier del presente número de Allpanchis constituye una versión en español, ampliada y revisada, a base de aquella publicación de Oesterreicher (2009), con reflexiones teóricas inéditas en español. 
de la evangelización. Así, en la publicación Esplendores y miserias de la evangelización de América. Antecedentes europeos y alteridad indígena (Oesterreicher y Schmidt-Riese 2010), que reunió las conferencias de unas jornadas internacionales realizadas en Múnich (1-3 de junio 2006), los principales aportes para el estudio del español en los Andes en el trasfondo de la evangelización trataron sobre:
a) textos coloniales bilingües (Garatea 2010a: 247-272, ${ }^{16}$ Rivarola 2010: 213-243).
b) tradiciones discursivas en la evangelización (Navarro Gala 2010: 183-212).
c) tipos de textos religiosos: libros de doctrineros (Guibovich 2010: 95-132).
d) categorización de los elementos lingüísticos en la gramática colonial andina (Schmidt-Riese 2010c: 133-162).
e) la infiltración de santos europeos en los textos coloniales americanos (Stoll 2010: 25-44).

Ese mismo año, y a manera de recuento de los avances en las investigaciones sobre el tema que aquí se trata, se llevó a cabo en el marco del Proyecto B5 el coloquio Formas de la pluralización del saber en el discurso catequético de la América colonial, en el que se expuso de qué manera el marco histórico, jurídico y social influyó en el discurso y la producción del español en los Andes coloniales, y se llegó a proponer:
a) la observación de indigenismos en el léxico ritual andino (Ezcurra).
b) el rastreo del trasfondo de la evangelización en textos jurídicos y administrativos (Huamanchumo).
c) la revisión de las formas de difusión del castellano en el virreinato del Perú (Kolbinger).

16. El profesor Garatea entretanto ha publicado un estudio sobre los orígenes del español del Perú (2010b) y un artículo sobre los orígenes del español andino (2013). 
Las conferencias de los investigadores señalados no fueron publicadas, puesto que eran adelantos de las tesis doctorales que estaban en proceso de elaboración. ${ }^{17}$

A ello se sumaría otro evento de mayor convocatoria, Universos semióticos, textualidad y legitimación de saberes en la América colonial (Múnich, 8-10 de diciembre, 2011), cuyos aportes se publicaron en el libro Conquista y conversión (Oesterreicher y Schmidt-Riese 2013), entre los que destacan en el tema que aquí se trata:

a) el planteamiento y desarrollo de la hipótesis sobre la historicidad de las fuentes míticas para el estudio del origen de los incas y la presencia del puquina en los Andes, cuestión elemental para las investigaciones sobre el español colonial (Cerrón-Palomino 2013: 21-35).

b) la propuesta sobre la revisión de la historia de guacas y las relaciones entre textos pastorales y discurso historiográfico (Ezcurra 2013a: 37-54).

c) la definición del perfil de los devocionarios coloniales (Guibovich 2013: 215-228).

d) el estudio del exemplum como recurso en las campañas de extirpación de idolatrías (Huamanchumo 2013a: 229-251).

e) el acceso a la escritura en las élites andinas (Kolbinger 2013: 301-324).

En general, a partir del análisis del discurso en textos religiosos, administrativos, jurídicos e historiográficos se buscó revisar los elementos semióticos, textuales y argumentativos que fueron construyendo América en el imaginario occidental y ayudaron a la asimilación del Nuevo Mundo a la corona española, acciones todas que no hubieran sido posible sin la conversión religiosa de los indígenas.

17. El programa completo y los títulos de las conferencias pueden verse en: <http:// www.sfb-frueheneuzeit.uni-muenchen.de/archiv/2010/b5nov10.html>. Las tesis doctorales resultantes se publicaron como libros en: Huamanchumo (2013b) y Ezcurra (2013b). El estudio doctoral de Kolbinger se encuentra en proceso de edición. 


\section{Comentario final}

La revisión hecha aquí de los estudios de hispanística en Alemania, en el tema de la historia del español de América, y el específico del español de los Andes coloniales durante la evangelización, demuestran que los métodos de análisis que primaron en las últimas tres décadas fueron los interdisciplinarios, concentrados en el análisis del discurso, como una entidad capaz de albergar elementos multifacéticos y como fuente inagotable de estudio. Del mismo modo, se ha visto que los estudios en las universidades alemanas han estado abiertos a la participación internacional, como se vislumbra y espera también para el futuro.

\section{REFERENCIAS}

Albertin, Chiara

2008 De las costumbres antiguas de los naturales del Pirú. Frankfurt am MainMadrid: Vervuert-Iberoamericana.

Cano Aguilar, Rafael

1996 «Lenguaje espontáneo y retórica epistolar en cartas de emigrantes españoles a Indias». En: Thomas Kotschi, Wulf Oesterreicher y Klaus Zimmermann (eds.). El español bablado y la cultura oral en España e Hispanoamérica. Madrid-Frankfurt a. M.: IberoamericanaVervuert, pp. 375-404.

1998 «Presencia de lo oral en lo escrito: transcripción de las declaraciones en los documentos indianos del siglo XVI». En: Wulf Oesterreicher, Eva Stoll y Andreas Wesch (eds.). Competencia escrita, tradiciones discursivas y variedades lingüísticas. Aspectos del español europeo y americano en los siglos ХИ у ХИІІ. Tübingen: Narr, pp. 219-242.

Cerrón-Palomino, Rodolfo

1976 «Calcos sintácticos en el castellano andino». San Marcos, n. 14, pp. 93-101.

2003 Castellano andino. Aspectos sociolingüísticos, pedagógicos y gramaticales. Lima: Fondo Editorial PUCP. 
2004 «La temprana andinización del castellano: testimonio de Ávalos y Figueroa (1602)». RILI-Revista Internacional de Lingüística Iberoamericana, vol. 2, n. 4, pp. 9-18.

2006 «Lingüística histórica y filología en el área andina». Boletín del Instituto Riva-Agüero, n. 33, pp. 109-127.

2013 «Cuando los mitos tienen un fondo de historicidad: el origen lacustre de los incas primordiales». En: Wulf Oesterreicher y Roland Schmidt-Riese (eds.). Conquista y conversión. Universos semióticos, textualidad y legitimación de saberes en la América colonial. Berlin-New York: De Gruyter, pp. 21-35.

EBERENZ, Rolf

1998 «La reproducción del discurso oral en las actas de la Inquisición (siglos XV y XVI)». En: Wulf Oesterreicher, Eva Stoll y Andreas Wesch (eds.). Competencia escrita, tradiciones discursivas y variedades lingüisticas. Aspectos del español europeo y americano en los siglos ХИ у ХИII. Tübingen: Narr, pp. 243-266.

Eberenz, Rolf y Mariela de la Torre

2003 Conversaciones estrechamente vigiladas. Interacción coloquial y español oral en las actas inquisitoriales de los siglos XV а ХИII. Zaragoza: Pórtico.

Esteve Barba, Francisco

1992 [1964] Historiografía indiana. 2a edición. Madrid: Gredos.

Ezcurra Rivero, Álvaro

2013a «Historias de guacas: textos pastorales y discurso historiográfico». En: Wulf Oesterreicher y Roland Schmidt-Riese (eds.). Conquista y conversión. Universos semióticos, textualidad y legitimación de saberes en la América colonial. Berlin-New York: De Gruyter, pp. 37-54.

2013b Dioses, bailes y cantos. Indigenismos rituales andinos en su historia. Tübingen: Narr.

Garatea Grau, Carlos

2008a «Textos bilingües y variedades del español de América (siglos Xvi y XVII)». En: Daniel Jacob y otros (eds.). Romanistisches Jabrbuch, n. 57. Berlin: De Gruyter, pp. 313-326.

2008b «Variedades en competencia o el registro del español andino». En: Roland Schmidt-Riese, Elisabeth Stark y Eva Stoll (eds.). Romanti- 
sche Syntax im Wandel. Festgabe zum 65. Geburtstag von Wulf Oesterreicher. Tübingen: Gunter Narr Verlag, pp. 643-660.

2010a «Textos coloniales bilingües. Ecos de orden y discurso impuestos». En: Wulf Oesterreicher y Roland Schmidt-Riese (eds.). Esplendores y miserias de la evangelización de América. Antecedentes europeos y alteridad indigena. Berlin: De Gruyter, pp. 247-272.

2010b Tras una lengua de papel. El español del Perú. Lima: PUCP.

2013 «Tras los orígenes del español andino. Problemas y realidades». Tinkuy, n. 20, pp. 126-137.

Guibovich, Pedro

2010 «Los libros de los doctrineros en el virreinato del Perú, siglos XVIXVII». En: Wulf Oesterreicher y Roland Schmidt-Riese (eds.). Esplendores y miserias de la evangelización de América. Antecedentes europeos y alteridad indigena. Berlin: De Gruyter, pp. 95-132.

2013 «Piedad popular y Contrarreforma: los devocionarios en el virreinato del Perú». En: Wulf Oesterreicher y Roland Schmidt-Riese (eds.). Conquista y conversión. Universos semióticos, textualidad y legitimación de saberes en la América colonial. Berlin-New York: De Gruyter, pp. 215-228.

Huamanchumo de la Cuba, Ofelia

2013a «El recurso discursivo del exemplum en la extirpación de las idolatrías (Perú-Siglo XVI)». En: Wulf Oesterreicher y Roland SchmidtRiese (eds.). Conquista y conversión. Universos semióticos, textualidad y legitimación de saberes en la América colonial. Berlin-New York: De Gruyter, pp. 229-251.

2013b Encomiendas y cristianización. Estudio de documentos jurídicos y administrativos del Perú. Siglo XVI. Piura: UDEP, Centro de Estudios Humanísticos.

JACOB, Daniel y Johannes Kabatek

2001a «Introducción: Lengua, texto y cambio lingüístico en la Edad Media Iberorománica». En: Daniel Jacob y Johannes Kabatek (eds.). Lengua medieval y tradiciones discursivas en la Peninsula Ibérica. Descripción gramatical-Pragmática histórica-Metodología. Madrid-Frankfurt a. M.: Iberoamericana-Vervuert, pp. vii-xviii.

JACOB, Daniel y Johannes Kabatek (eds.)

2001b Lengua medieval y tradiciones discursivas en la Peninsula Ibérica. Descripción 
gramatical-Pragmática histórica-Metodología. Madrid-Frankfurt a. M.: Iberoamericana-Vervuert.

KaBATEK, Johannes

2001 «Cómo investigar las tradiciones discursivas medievales? El ejemplo de los textos jurídicos castellanos». En: Daniel Jacob y Johannes Kabatek (eds.). Lengua medieval y tradiciones discursivas en la Peninsula Ibérica. Descripción gramatical-Pragmática histórica-Metodología. Madrid-Frankfurt a. M.: Iberoamericana-Vervuert, pp. 97-132.

2005 «Tradiciones discursivas y cambio lingüístico». Lexis: Revista de Lingüística y Literatura, vol. 29, n. 2, pp. 151-177.

2008 «Introducción». En: Johannes Kabatek (ed.). Sintaxis histórica de español y cambio lingüistico. Nuevas perspectivas desde las tradiciones discursivas. Madrid-Frankfurt a. M.: Iberoamericana-Vervuert, pp. 7-16.

2014 «El hispanismo y los países germanófonos: de sus inicios en el romanticismo al siglo XVI». En: El español en el mundo (Anuario del Instituto Cervantes). Madrid: Ministerio de la Presidencia, pp. 183-201.

KocH, Peter y Wulf Oesterreicher

2007 Lengua hablada en la Romania. Español, francés, italiano. Traducción de Araceli López Serena. Madrid: Gredos.

KolBinger, Ulrike

2013 «Juristisch-administrative Schriftlichkeit und indigene Eliten Bittschriften aus dem Mantaro-Tal im 17. Jahrhundert (Peru, 17. Jahrhundert)». En: Wulf Oesterreicher y Roland Schmidt-Riese (eds.). Conquista y conversión. Universos semióticos, textualidad y legitimación de saberes en la América colonial. Berlin-New York: De Gruyter, pp. 301-324.

Kотsсні, Thomas, Wulf Oesterreicher y Klaus Zimmermann (eds.)

1996 El español hablado y la cultura oral en España e Hispanoamérica. MadridFrankfurt a. M.: Iberoamericana-Vervuert.

LÜDTKE, Jens (ed.)

1994 El español de América en el siglo XVI. Actas del Simposio del Instituto IberoAmericano de Berlin, 23 y 24 de abril de 1992. Madrid-Frankfurt a.

M.: Iberoamericana-Vervuert. 
LÜDTKE, Jens y Matthias Perl (eds.)

1994 Lengua y cultura en el Caribe hispánico. Actas de una sección del Congreso de la Asociación de Hispanistas Alemanes, Augsburgo, 4-7 de marzo de 1993. Tübingen: Niemeyer.

Martínez, Angelita y Azucena Palacios (coord.)

2010 «Sección temática: El español en contacto con otras lenguas en América». RILI-Revista Internacional de Lingüistica Iberoamericana, n. 1 (15), vol. 8, pp. 9-184.

Navarro Gala, Rosario

2010 «Evangelización española y tradiciones discursivas en el Perú del siglo XVII». En: Wulf Oesterreicher y Roland Schmidt-Riese (eds.). Esplendores y miserias de la evangelización de América. Antecedentes europeos y alteridad indígena. Berlin: De Gruyter, pp. 183-212.

Neumann-Holzschuh, Ingrid, Volker Noll y Klaus Zimmermann (eds.) 2005 El español en América. Aspectos teóricos, particulares, contactos. MadridFrankfurt: Iberoamericana-Vervuert.

NeusChÄFER, Hans-Jörg

1996 «La situación de la hispanística en las universidades alemanas». Revista de Hispanismo Filosófico, n. 1, pp. 77-80.

Oesterreicher, Wulf

1994a «El español en textos escritos por semicultos. Competencia escrita de impronta oral en la historiografía indiana (siglo XVI)». En: Jens Lüdtke (ed.). El español de América en el siglo XVI. Actas del Simposio del Instituto Ibero-Americano de Berlín, 23 y 24 de abril de 1992. Madrid; Frankfurt a. M.: Iberoamericana-Vervuert, pp. 155-190.

1994b «Kein sprachlicher Alltag-Der Konquistador Alonso Borregán schreibt eine Chronik». En: Anette Sabban y Christian Schmitt (eds.). Sprachlicher Alltag. Linguistik, Rhetorik, Literatur. Festschrift für Wolf-Dieter Stempel, 7.Jul.94. Tübingen: Niemeyer, pp. 379-418.

1995 «Das Massaker von Cholula, México, 1519. Ein Ereignis-unterschiedliche Darstellungen». En: Wolfgang Raible (ed.). Kulturelle Perspektiven auf Schrift und Schreibprozesse. Elf Aufsätze zum Thema Mündlichkeit und Schriftlichkeit, Tübingen: Narr, pp. 98-120. 
1996 «Lo hablado en lo escrito: reflexiones metodológicas y aproximaciones a una tipología». En: Thomas Kotschi, Wulf Oesterreicher y Klaus Zimmermann (eds.). El español hablado y la cultura oral en España e Hispanoamérica. Madrid; Frankfurt a. M.: IberoamericanaVervuert, pp. 317-340.

1997 «Cajamarca 1532. Diálogo y violencia. Los cronistas y la elaboración de una historia andina». En: Lexis: Revista de Lingüística y Literatura, vol. 21, n. 2, pp. 211-271.

2001 «La «recontextualización» en los géneros medievales como tarea hermenéutica». En: Daniel Jacob y Johannes Kabatek (eds.). Lengua medieval y tradiciones discursivas en la Peninsula Ibérica. Descripción gramatical-Pragmática histórica-Metodología. Madrid-Frankfurt a. M.: Iberoamericana-Vervuert, pp. 199-231.

2003 «Las otras Indias. Estrategias de cristianización en América y en Europa, la lingüística misionera y el estatus del latín». En: José Luis Girón Alconchel y otros (eds.). Estudios ofrecidos al profesor José Jesús de Bustos Tovar. Tomo I. Madrid: Instituto de Estudios Almerienses, pp. 463-480.

2005 «Talleres de la memoria- textos, espacios discursivos y realidad colonial». En: Robert Folger y Wulf Oesterreicher (eds.). Talleres de la memoria-reivindicaciones y autoridad en la historiografia indiana de los siglos ХИІ $y$ XИII. Münster: LIT.

2009 «Los otros piratas de América-Information und Autorschaft in amerikanischen Texten der Frühen Neuzeit». En: Mitteilungen des SFB 573 Pluralisierung und Autorität in der Frühen Neuzeit (15.-17. Jabrbundert), n. 1, pp. 32-50.

Oesterreicher, Wulf y Roland Schmidt-Riese (eds.)

2010 Esplendores y miserias de la evangelización de América. Antecedentes europeos $y$ alteridad indigena. Berlin: De Gruyter.

2013 Conquista y conversión. Universos semióticos, textualidad y legitimación de saberes en la América colonial. Berlin-New York: De Gruyter.

Oesterreicher, Wulf, Eva Stoll y Andreas Wesch (eds.)

1998 Competencia escrita, tradiciones discursivas y variedades lingüisticas. Aspectos del español europeo y americano en los siglos XVI y XVII. Tübingen: Narr. 
Rivarola, José Luis

1989 «Bilingüismo histórico y español andino». En: Actas del IX Congreso de la Asociación Internacional de Hispanistas, Berlin, 18-23 de agosto de 1986. Vol. I. Frankfurt a. M.: Vervuert, pp. 153-163.

1994 «Escrituras marginales: sobre textos bilingües en el Perú del siglo XVI». En: Jens Lüdtke (ed.). El español de América en el siglo ХVI. Actas del Simposio del Instituto Ibero-Americano de Berlín, 23 y 24 de abril de 1992. Madrid-Frankfurt a. M.: Iberoamericana-Vervuert, pp. 191-209.

1995 «Aproximación histórica a los contactos de lenguas en el Perú». En: Klaus Zimmermann (ed.). Lenguas en contacto en Hispanoamérica. Nuevos enfoques. Madrid-Frankfurt a. M.: Iberoamericana-Vervuert, pp. 135-159.

2000 Español andino. Textos bilingües de los siglos ХИ у ХИІІ. Madrid-Frankfurt a. M.: Iberoamericana-Vervuert.

2008 «Un corpus del español del Perú 1546-1697. Reflexiones y perspectivas». En: Roland Schmidt-Riese, Elisabeth Stark y Eva Stoll (eds.). Romantische Syntax im Wandel. Festgabe zum 65. Geburtstag von Wulf Oesterreicher. Tübingen: Gunter Narr Verlag, pp. 661-671.

2009 Documentos lingüisticos del Perú. Siglos XI y ХИII. Madrid: CSIC.

2010 «Los indios capitulan a su cura. Sobre lengua y sociedad en el Perú andino del siglo XVII». En: Wulf Oesterreicher y Roland SchmidtRiese (eds.). Esplendores y miserias de la evangelización de América. Antecedentes europeos y alteridad indígena. Berlin: De Gruyter, pp. 213-243.

Roth, Wolfgang

1995 «Sobre la influencia de las lenguas amerindias en el castellano». En: Klaus Zimmermann (ed.). Lenguas en contacto en Hispanoamérica. Nuevos enfoques. Madrid-Frankfurt a. M.: Iberoamericana-Vervuert, pp. 35-50.

SCHARLAU, Birgit

1990 «Nuevas tendencias en los estudios de crónicas y documentos del periodo colonial latinoamericano». Revista de Crítica Literaria Latinoamericana, n. 31-32, año 16, pp. 365-375.

SCHMIDT-RIESE, Roland

2004 Reducere ad artem». Zur Transformation grammatischer Kategorien am 
Diskursort Mission. Spanische, portugiesische und franzö̈ische Amerindia, 1547-1700. [Habilitationsschrift, LMU München].

2010a Catequesis y derecho en la América colonial: fronteras borrosas. MadridFrankfurt a. M.: Iberoamericana-Vervuert.

2010b «Grammatiken auf amerikanischen Boden: Bausteine einer virtuellen Bibliothek». En: Jan-Dirk Müller, Wulf Oesterreicher y Friedrich Vollhardt (eds.). Pluralisierungen: Konzepte zur Erfassung der Frühen Neuzeit. Berlin: De Gruyter, pp. 303-320.

2010c «Transiciones: categorización en la gramática colonial andina hacia 1600». En: Wulf Oesterreicher y Roland Schmidt-Riese (eds.). Esplendores y miserias de la evangelización de América. Antecedentes europeos y alteridad indígena. Berlin: De Gruyter, pp. 133-162.

Schmidt-RieSE, Roland, Elisabeth Stark y Eva Stoll (eds.)

2008 Romantische Syntax im Wandel. Festgabe zum 65. Geburtstag von Wulf Oesterreicher. Tübingen: Gunter Narr Verlag.

STOLL, Eva

1997 Konquistadoren als Historiographen. Diskurstraditionelle und textpragmatische Aspekte in Texten von Francisco de Jerez, Diego de Trujillo und Alonso Borregán. Tübingen: Narr.

1998 «Géneros en la historiografía indiana: modelos y transformaciones». En: Wulf Oesterreicher, Eva Stoll y Andreas Wesch (eds.). Competencia escrita, tradiciones discursivas y variedades lingüisticas. Aspectos del español europeo y americano en los siglos XVI y XVII. Tübingen: Narr, pp. 143-168.

2002 La Memoria de Juan Ruiz de Arce. Conquista del Perú, saberes secretos de caballería y defensa del mayorazgo. Frankfurt am Main-Madrid: Vervuert-Iberoamericana.

2010 «La exportación de los santos al Nuevo Mundo-Modelos, motivos y malentendidos». En: Wulf Oesterreicher y Roland Schmidt-Riese (eds.). Esplendores y miserias de la evangelización de América. Antecedentes europeos y alteridad indigena. Berlin: De Gruyter, pp. 25-44.

2013 «Paratextos en la historiografía indiana del siglo xvI-Particularidades en las obras de semicultos». En: Wulf Oesterreicher y Roland Schmidt-Riese (eds.). Conquista y conversión. Universos semióticos, textualidad y legitimación de saberes en la América colonial. Berlin-New York: De Gruyter, pp. 255-276. 
STOLL, Eva y María de la Nieves Vázquez Núñez (eds.)

2011 Alonso Borregán. La Conquista del Perú. Edición en colaboración con Sebastian Greußlich y Marta Guzmán. Con un estudio introductorio de Wulf Oesterreicher. Madrid-Frankfurt a. M.: Iberoamericana-Vervuert.

WeSCH, Andreas

1993 Kommentierte Edition und linguistische Untersuchung der Information de los Jerónimos (Santo Domingo 1517). Tübingen: Gunter Narr Verlag.

1994 «El documento indiano y las tradiciones textuales en los siglos XV y xvi: la clase textual Información». En: Jens Lüdtke (ed.). El español de América en el siglo XVI. Actas del Simposio del Instituto Ibero-Americano de Berlin, 23 y 24 de abril de 1992. Madrid; Frankfurt a. M.: Iberoamericana-Vervuert, pp. 57-71.

1998 «Hacia una tipología lingüística de los textos administrativos y jurídicos españoles (siglos XV-XVII)». En: Wulf Oesterreicher, Eva Stoll y Andreas Wesch (eds.). Competencia escrita, tradiciones discursivas y variedades lingüisticas. Aspectos del español europeo y americano en los siglos хИл у ХИІ. Tübingen: Narr, pp. 187-217.

Zimmermann, Klaus

2004 «La construcción del objeto de la historiografía lingüística misionera». En: Otto Zwartjes y Even Hovdhaugen (eds.). Missionary Linguistics / Lingüistica misionera. Selected Papers from the First International Conference on Missionay Linguistics, (Oslo, 13-16 de marzo de 2003), Amsterdam-Philadelphia: John Benjamins, pp. 8-32.

1997 La descripción de las lenguas amerindias en la época colonial. MadridFrankfurt a. M.: Iberoamericana-Vervuert.

1995a «Aspectos teóricos y metodológicos de la investigación sobre el contacto de lenguas en Hispanoamérica». En: Klaus Zimmermann (ed.). Lenguas en contacto en Hispanoamérica, Madrid: Biblioteca Iberoamericana, pp. 9-34.

Zimmermann, Klaus (ed.)

1995b Lenguas en contacto en Hispanoamérica. Nuevos enfoques. MadridFrankfurt a. M.: Iberoamericana-Vervuert. 